\title{
Thermodynamic Properties of Organic Compounds. 3. Sublimation Enthalpy and Heat Capacities of 2,4,6-Trimethylbenzonitrile $\mathrm{N}$-Oxide
}

\author{
William E. Acree, Jr.* \\ Department of Chemistry, University of North Texas, Denton, Texas 76203-5068 \\ Viktor M. Sevruk, Alexander A. Kozyro, Alexander P. Krasulin, and Gennady J. Kabo \\ Department of Chemistry, Byelorussian State University, Minsk 220080, Belarus
}

Michael L. Frenkel

Thermodynamics Research Center, Texas A\&M University, College Station, Texas 77843-3111

\begin{abstract}
Experimental heat capacities $(6-319 \mathrm{~K})$ and enthalpy of sublimation, $\Delta_{\text {sub }} H^{\circ}{ }_{\mathrm{m}}(313.5 \mathrm{~K})=87.52 \pm 0.53 \mathrm{~kJ}$ $\mathrm{mol}^{-1}$, are reported for 2,4,6-trimethylbenzonitrile $N$-oxide. Heat capacity data show a reversible solid-phase transition in the 217-235 K temperature interval, for which the following thermodynamic functions have been computed: $T_{\mathrm{tr}}=224.3 \mathrm{~K} ; \Delta_{\mathrm{tr}} H_{\mathrm{m}}=80 \pm 4 \mathrm{~J} \mathrm{~mol}^{-1} ; \Delta_{\mathrm{tr}} S=0.35 \pm 0.02 \mathrm{~J} \mathrm{~mol}^{-1} \mathrm{~K}^{-1}$. Thermodynamic properties of 2,4,6-trimethylbenzonitrile $N$-oxide in the condensed state are tabulated at every 5 or $10 \mathrm{~K}$ interval throughout the 0-320 $\mathrm{K}$ temperature interval.
\end{abstract}

\section{Introduction}

Nitrile $N$-oxides are highly reactive organic compounds prepared from oxidation of aldoximes and dehydration of nitro compounds. Reported half-lives of aliphatic nitrile $N$-oxides range from a few seconds to minutes before rearrangement to isocyanates or polymerization occurs. Aromatic nitrile $N$-oxides are considerably more stable, particularly 1,4-dicyanobenzene di- $N$-oxide $(1,2)$, which can be stored for several months without noticeable degradation. Bulky substituents in the ortho positions of the benzene ring or on the $\alpha$-carbon aliphatic derivatives enhance stability. Sterically hindered nitrile $N$-oxides such as 2,6-dimethylbenzonitrile $N$-oxide and di-tert-butylacetonitrile $N$-oxide are "permanently stable" at room temperature (3-5).

Chemical reactivity of the nitrile $N$-oxides undoubtedly arises because of the ionic nature of the $\mathrm{N}-\mathrm{O}$ dative bond. Nuclear magnetic resonance ${ }^{13} \mathrm{C}$ chemical shift data for 2,4,6trimethylbenzonitrile $N$-oxide (6) suggest that the carbon atom carries substantial negative charge (i.e., the $\mathrm{R}-\mathrm{C}=\mathrm{N}^{+}=\mathrm{O}$ resonance form) and are in accord with published X-ray crystallographic bond distances for 4-methoxy-2,6-dimethylbenzonitrile $N$-oxide (7). Surprisingly, very few precise thermochemical quantities are available in the literature for nitrile $N$-oxides. Acree, Pilcher, and co-workers $(8,9)$ previously reported the standard enthalpies of combustion and sublimation for 2,4,6-trimethylbenzonitrile $N$ oxide, 2,4,6-trimethoxybenzonitrile $N$-oxide, and 1,4-dicyanobenzene di- $N$-oxide as determined by static bomb calorimetric, "vacuum sublimation" drop microcalorimetric, and Knudsen effusion vapor pressure methods, respectively. Because of the scarcity of experimental data for this relatively novel class of compounds, particularly low-temperature thermodynamic data, we initiated a comprehensive thermodynamic study of 2,4,6-trimethylbenzonitrile $N$-oxide, which included a recently published redetermination of the enthalpy of combustion (10), as well as heat capacity and sublimation measurements. In this paper we report results from the heat capacity and sublimation measurements.

- To whom correspondence should be addressed.

\section{Experimental Methods}

2,4,6-Trimethylbenzonitrile $N$-oxide was prepared by the procedures outlined by Grundmann and Dean (5) and Beltrame etal. (11). Hydroxylamine hydrochloride was added to a hot solution of 2,4,6-trimethylbenzaldehyde in methanol, and the resulting aldoxime was converted to the nitrile $N$-oxide with sodium hypobromite. The crude sample was further purified by three recrystallizations from a benzene-hezane mixture. Elemental analysis on the purified sample was in excellent agreement with calculated values. Anal. Calcd for $\mathrm{C}_{10} \mathrm{H}_{11} \mathrm{NO}$ : C, 74.51; H, 6.88; N, 8.69. Found: C, 74.58; H, 6.94; N, 8.62. High-performance liquid chromatographic analysis with ultraviolet detection at $254 \mathrm{~nm}$ further showed that the sample contained a single minor impurity. The sample purity was estimated to be $99.8+\%$ on the basis of the areas under the two observed chromatographic peaks, assuming identical detector responses for both 2,4,6-trimethylbenzonitrile $N$-oxide and the unidentified impurity, which was likely unreacted 2,4,6-trimethylbenzaldehyde or a reaction byproduct. The sample was stored in a cool, dark place for several weeks and shipped to the Soviet Union via air mail during a period of heightened airport security.

Experimental procedures and instrumentation are described in detail elsewhere $(12,13)$. Briefly, the heat capacity was measured in a vacuum adiabatic calorimeter TAU-1, fabricated by VNIIFTRI (National Scientific and Research Institute for Physical-technical and Radio-technical Measurements) in Moscow. The investigated sample (tablet with mass of $0.53734 \mathrm{~g}$ ) was put in a stainless-steel ampule filled with heat-exchange helium gas and sealed with an indium gasket. A small drop of silicon polymer (CKTH) was placed on the external surface of the ampule to improve heat exchange between the ampule and calorimetric device. The ampule was tightly inserted into the calorimetric sleeve and provided with a Manganin heater. The sleeve was suspended by three nylon cords within the adiabatic shield, which was also provided with a Manganin heater. The relative temperature between the adiabatic shield and the calorimetric sleeve was determined by a four-junction differential thermocouple: $(0.999 \mathrm{Cu}+0.001 \mathrm{Fe})$-to-Chromel. The electric potential of 
Table 1. Experimental Molar Heat Capacities of Crystalline 2,4,6-Trimethylbenzonitrile $\mathbf{N}$-Oxide

\begin{tabular}{|c|c|c|c|c|c|c|c|c|c|c|c|}
\hline$\langle T\rangle / \mathbf{K}$ & $\Delta T / \mathbf{K}$ & $C_{p, \mathrm{~m}} / R^{a}$ & $\langle T\rangle / \mathrm{K}$ & $\Delta T / \mathbf{K}$ & $C_{p, \mathrm{mo}} / R^{a}$ & $\langle T\rangle / \mathbf{K}$ & $\Delta T / \mathbf{K}$ & $C_{p, \mathrm{~m}} / R^{\mathrm{a}}$ & $\langle T\rangle / \mathrm{K}$ & $\Delta T / \mathrm{K}$ & $C_{p, \mathrm{~m}} / R^{a}$ \\
\hline $\begin{array}{l}5.974 \\
6.290 \\
6.674 \\
7.100 \\
7.716 \\
8.321 \\
8.808\end{array}$ & $\begin{array}{l}0.1786 \\
0.3712 \\
0.3396 \\
0.4594 \\
0.5557 \\
0.4991 \\
0.4487\end{array}$ & $\begin{array}{l}0.1031 \\
0.1179 \\
0.1337 \\
0.1567 \\
0.1970 \\
0.2382 \\
0.2788\end{array}$ & $\begin{array}{c}9.319 \\
9.955 \\
10.64 \\
11.25 \\
11.80 \\
12.43 \\
13.14\end{array}$ & $\begin{array}{l}0.5405 \\
0.7041 \\
0.6183 \\
0.5584 \\
0.5109 \\
0.7221 \\
0.6562\end{array}$ & $\begin{array}{l}\quad \text { Seri } \\
0.3211 \\
0.3979 \\
0.4749 \\
0.5401 \\
0.6044 \\
0.6869 \\
0.7645\end{array}$ & $\begin{array}{l}13.78 \\
14.36 \\
14.63 \\
15.10 \\
15.96 \\
16.48 \\
16.74\end{array}$ & $\begin{array}{l}0.5978 \\
0.5509 \\
1.0314 \\
0.8938 \\
0.8040 \\
0.8243 \\
0.7323\end{array}$ & $\begin{array}{l}0.8550 \\
0.9413 \\
0.9830 \\
1.041 \\
1.173 \\
1.254 \\
1.301\end{array}$ & $\begin{array}{l}17.28 \\
17.46 \\
18.01 \\
18.69 \\
20.24 \\
20.98\end{array}$ & $\begin{array}{l}0.7544 \\
0.6791 \\
0.6967 \\
0.6488 \\
0.7611 \\
0.7106\end{array}$ & $\begin{array}{l}1.376 \\
1.406 \\
1.495 \\
1.609 \\
1.859 \\
1.985\end{array}$ \\
\hline $\begin{array}{l}5.744 \\
5.967 \\
6.283 \\
6.670 \\
7.026 \\
7.488 \\
7.966 \\
8.129 \\
8.501 \\
8.846 \\
9.618\end{array}$ & $\begin{array}{l}0.1926 \\
0.1845 \\
0.3783 \\
0.3449 \\
0.3174 \\
0.4975 \\
0.4442 \\
0.3647 \\
0.3376 \\
0.3159 \\
0.4373\end{array}$ & $\begin{array}{l}0.09582 \\
0.09959 \\
0.1189 \\
0.1362 \\
0.1533 \\
0.1783 \\
0.2119 \\
0.2308 \\
0.2564 \\
0.2797 \\
0.3554\end{array}$ & $\begin{array}{l}10.27 \\
10.89 \\
11.46 \\
12.05 \\
12.66 \\
13.21 \\
13.72 \\
14.25 \\
14.81 \\
15.53 \\
16.00\end{array}$ & $\begin{array}{l}0.6392 \\
0.5678 \\
0.5153 \\
0.6123 \\
0.5590 \\
0.5167 \\
0.4841 \\
0.5052 \\
0.5268 \\
0.7614 \\
0.5687\end{array}$ & $\begin{array}{l}\quad \text { Seri } \\
0.4290 \\
0.5039 \\
0.5704 \\
0.6373 \\
0.7115 \\
0.7799 \\
0.8367 \\
0.9265 \\
1.001 \\
1.107 \\
1.177\end{array}$ & $\begin{array}{l}2 \\
16.52 \\
17.58 \\
19.40 \\
20.13 \\
20.83 \\
21.88 \\
23.17 \\
24.29 \\
25.48 \\
26.89 \\
28.46\end{array}$ & $\begin{array}{l}0.6801 \\
0.4759 \\
0.7012 \\
0.6381 \\
0.8129 \\
1.2673 \\
1.1115 \\
1.0634 \\
1.4859 \\
1.3436 \\
1.7846\end{array}$ & $\begin{array}{l}1.251 \\
1.421 \\
1.720 \\
1.850 \\
1.968 \\
2.132 \\
2.356 \\
2.534 \\
2.722 \\
2.959 \\
3.197\end{array}$ & $\begin{array}{l}33.06 \\
34.45 \\
35.84 \\
37.13 \\
38.87 \\
40.98 \\
43.15 \\
45.37 \\
49.50 \\
51.61\end{array}$ & $\begin{array}{l}1.3523 \\
1.4410 \\
1.3371 \\
1.2497 \\
2.2212 \\
2.0289 \\
2.3347 \\
2.1396 \\
2.1912 \\
2.0502\end{array}$ & $\begin{array}{l}3.950 \\
4.220 \\
4.470 \\
4.713 \\
4.905 \\
5.233 \\
5.488 \\
5.812 \\
6.433 \\
6.736\end{array}$ \\
\hline $\begin{array}{l}52.85 \\
56.20 \\
60.44 \\
66.53\end{array}$ & $\begin{array}{l}2.8425 \\
3.8732 \\
4.6442 \\
7.5672\end{array}$ & $\begin{array}{l}6.858 \\
7.366 \\
7.948 \\
8.768\end{array}$ & $\begin{array}{l}74.12 \\
81.72 \\
85.81 \\
89.54\end{array}$ & $\begin{array}{l}5.2151 \\
4.3613 \\
3.8208 \\
3.6447\end{array}$ & $\begin{array}{c}\text { Seri } \\
9.761 \\
10.68 \\
11.10 \\
11.50\end{array}$ & $\begin{array}{r}3 \\
93.11 \\
96.99 \\
100.99 \\
104.90\end{array}$ & $\begin{array}{l}3.4957 \\
3.7450 \\
3.9800 \\
3.8390\end{array}$ & $\begin{array}{l}11.88 \\
12.31 \\
12.68 \\
13.08\end{array}$ & $\begin{array}{l}108.67 \\
112.30\end{array}$ & $\begin{array}{l}3.7151 \\
3.6203\end{array}$ & $\begin{array}{l}13.48 \\
13.80\end{array}$ \\
\hline $\begin{array}{l}69.27 \\
73.97 \\
78.38 \\
86.39 \\
90.10 \\
93.65 \\
97.06\end{array}$ & $\begin{array}{l}3.0533 \\
4.5687 \\
4.2488 \\
3.7901 \\
3.6183 \\
3.4731 \\
3.3472\end{array}$ & $\begin{array}{l}9.108 \\
9.755 \\
10.28 \\
11.17 \\
11.58 \\
11.95 \\
12.32\end{array}$ & $\begin{array}{l}100.82 \\
104.93 \\
108.89 \\
112.73 \\
116.45 \\
120.09 \\
123.63\end{array}$ & $\begin{array}{l}4.1825 \\
4.0285 \\
3.8945 \\
3.7763 \\
3.6737 \\
3.5830 \\
3.5022\end{array}$ & $\begin{array}{l}\quad \text { Seri } \\
12.67 \\
13.08 \\
13.47 \\
13.85 \\
14.21 \\
14.52 \\
14.84\end{array}$ & $\begin{array}{l}4 \\
127.10 \\
130.50 \\
135.90 \\
142.90 \\
147.70 \\
152.46 \\
157.10\end{array}$ & $\begin{array}{l}3.4300 \\
3.3597 \\
4.8949 \\
4.8359 \\
4.7295 \\
4.6343 \\
4.5454\end{array}$ & $\begin{array}{l}15.11 \\
15.41 \\
15.76 \\
16.22 \\
16.61 \\
16.98 \\
17.39\end{array}$ & $\begin{array}{l}161.66 \\
166.14 \\
170.56 \\
174.92 \\
179.22\end{array}$ & $\begin{array}{l}4.4656 \\
4.3922 \\
4.3232 \\
4.2615 \\
4.2025\end{array}$ & $\begin{array}{l}17.76 \\
18.14 \\
18.51 \\
18.86 \\
19.21\end{array}$ \\
\hline $\begin{array}{l}182.73 \\
189.05\end{array}$ & $\begin{array}{l}6.2998 \\
6.1818\end{array}$ & $\begin{array}{l}19.49 \\
20.04\end{array}$ & $\begin{array}{l}196.14 \\
203.97\end{array}$ & $\begin{array}{l}7.8026 \\
7.6388\end{array}$ & $\begin{array}{l}\text { Seri } \\
20.60 \\
21.30\end{array}$ & $\begin{array}{l}5 \\
211.66 \\
216.95\end{array}$ & $\begin{array}{l}7.4946 \\
5.3945\end{array}$ & $\begin{array}{l}21.97 \\
22.43\end{array}$ & 219.22 & 7.3655 & 22.62 \\
\hline $\begin{array}{l}219.86 \\
221.26 \\
221.73 \\
222.57 \\
222.78 \\
222.99\end{array}$ & $\begin{array}{l}0.2019 \\
1.1486 \\
0.1706 \\
0.1705 \\
0.1698 \\
0.1695\end{array}$ & $\begin{array}{l}22.81 \\
23.07 \\
23.18 \\
23.30 \\
23.43 \\
23.56\end{array}$ & $\begin{array}{l}223.07 \\
224.09 \\
224.31 \\
224.54 \\
224.76 \\
224.98\end{array}$ & $\begin{array}{l}1.1401 \\
0.1689 \\
0.1688 \\
0.1695 \\
0.1692 \\
0.1698\end{array}$ & $\begin{array}{l}\quad \text { Seri } \\
23.48 \\
23.71 \\
23.74 \\
23.40 \\
23.52 \\
23.22\end{array}$ & \begin{tabular}{l}
\multicolumn{1}{l}{6} \\
225.48 \\
227.01 \\
227.92 \\
228.35 \\
230.31 \\
231.04
\end{tabular} & $\begin{array}{l}1.1402 \\
0.1697 \\
0.1680 \\
2.6178 \\
1.1402 \\
2.6235\end{array}$ & $\begin{array}{l}23.25 \\
23.14 \\
23.01 \\
23.01 \\
22.81 \\
22.61\end{array}$ & $\begin{array}{l}231.52 \\
232.73 \\
233.73 \\
235.20\end{array}$ & $\begin{array}{l}1.1393 \\
1.1403 \\
2.6160 \\
1.1370\end{array}$ & $\begin{array}{l}22.77 \\
22.61 \\
22.61 \\
22.62\end{array}$ \\
\hline $\begin{array}{l}238.57 \\
241.76 \\
244.87 \\
249.20\end{array}$ & $\begin{array}{l}5.2786 \\
2.5808 \\
2.9607 \\
5.1752\end{array}$ & $\begin{array}{l}22.86 \\
23.05 \\
23.29 \\
23.61\end{array}$ & $\begin{array}{l}254.46 \\
259.68 \\
264.86 \\
269.97\end{array}$ & $\begin{array}{l}5.1240 \\
5.0752 \\
5.0123 \\
4.9344\end{array}$ & $\begin{array}{l}\quad \text { Seri } \\
24.02 \\
24.46 \\
25.14 \\
26.10\end{array}$ & $\begin{array}{l}7 \\
275.66 \\
281.94 \\
288.20 \\
294.46\end{array}$ & $\begin{array}{l}6.1069 \\
6.0466 \\
6.0059 \\
5.9578\end{array}$ & $\begin{array}{l}26.89 \\
27.38 \\
27.68 \\
28.09\end{array}$ & $\begin{array}{l}300.71 \\
306.91 \\
313.05 \\
319.22\end{array}$ & $\begin{array}{l}5.8991 \\
5.7993 \\
5.6867 \\
5.5870\end{array}$ & $\begin{array}{l}28.67 \\
29.90 \\
31.40 \\
32.81\end{array}$ \\
\hline
\end{tabular}

a Note: The mean molar $C_{p, \mathrm{~m}}$ in the temperature interval $\Delta T$ are given at the mean temperature $\langle T\rangle . R=8.31451 \mathrm{~J} \mathrm{~mol}^{-1} \mathrm{~K}^{-1}$.

the thermocouple after preliminary amplification went to the terminals of an analogue regulation block, which assured automatic adiabatic shield control with proportional integral/ differential action. The thermometric measurements were made by a capsule-type (rhodium $+0.5 \%$ atomic $\mathrm{Fe}$ ) resistance thermometer $\left(R_{0}=45.32 \Omega\right)$ installed on the inner surface of the adiabatic shield. The thermometer was fabricated and calibrated by VNIIFTRI. The reliability of the calorimetric apparatus was established by measuring the heat capacities of standard benzoic acid K-1 and high-purity copper [sample OSCh 11-4, standard of USSR]. The probable error of the heat capacity values is approximately $2 \%$ at liquid helium temperature and $1 \%$ in the interval $15-20 \mathrm{~K}$, decreases to $0.4 \%$ for temperatures up to $40 \mathrm{~K}$, and does not exceed $0.4 \%$ from 40 to $320 \mathrm{~K}$. Heat capacities of all auxiliary substances were included in the 2,4,6-trimethylbenzonitrile $N$-oxide heat capacity calculations. The heat capacities of the sample at temperatures 10,100 , and $300 \mathrm{~K}$ were approximately $45 \%, 30 \%$, and $35 \%$ of the total heat capacity of the calorimeter, respectively.

The sublimation enthalpy of 2,4,6-trimethylbenzonitrile $N$-oxide was determined by a heat-conduction calorimeter of the Calvet type (13). We constructed two vacuum calorimetric cells (A and $B$ ) for measuring enthalpies of vaporization in accordance with the ampule method to be used with a commercially available differential microcalorimeter MID2000 . The cells were calibrated by enthalpies of vaporization of four reference substances: benzoic acid K-1, naphthalene twice sublimed from a sample "pure for analysis" (standard of the USSR), $n$-decane of gas chromatographic standard grade, and doubly distilled water. The studied substances (mass from 0.01 to $0.15 \mathrm{~g}$ ) were preliminarily outgassed in vacuum and sealed in glass ampules. Despite the significant differences of saturated vapor pressures of these reference substances $(2-3160 \mathrm{~Pa})$ at the experimental temperatures (293-342 K), we obtained in all cases practically identical 


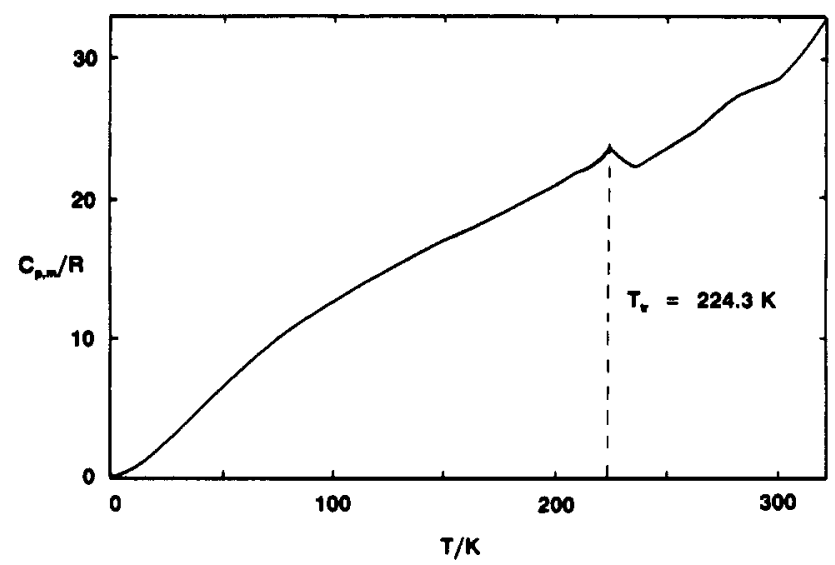

Figure 1. Temperature dependence of $C_{p, \mathrm{~m}} / R$ of 2,4,6trimethylbenzonitrile $N$-oxide. The vertical line indicates the temperature of the phase transition. The solid curve represents the "smoothed" heat capacity data.

Table II. Molar Thermodynamic Functions of 2,4,6-Trimethylbenzonitrile $\mathrm{N}$-Oxide at Select Temperatures

\begin{tabular}{|c|c|c|c|c|}
\hline$T / \mathbf{K}$ & $C_{p, \mathrm{~m}} / R$ & $\Delta^{0}{ }_{T} S^{\circ}{ }_{\mathrm{m}} / R$ & $\Delta^{\circ}{ }_{T} H^{\circ}{ }_{\mathrm{m}} / R T$ & $\Phi_{\mathrm{m}}^{\circ}(T, 0) / R$ \\
\hline 0 & 0 & 0 & 0 & 0 \\
\hline 5 & 0.05836 & 0.01945 & 0.01459 & 0.004863 \\
\hline 10 & 0.3993 & 0.1432 & 0.1058 & 0.03735 \\
\hline 15 & 1.032 & 0.4183 & 0.3036 & 0.1147 \\
\hline 20 & 1.823 & 0.8202 & 0.5819 & 0.2383 \\
\hline 25 & 2.652 & 1.317 & 0.9140 & 0.4034 \\
\hline 30 & 3.451 & 1.871 & 1.270 & 0.6009 \\
\hline 35 & 4.311 & 2.466 & 1.641 & 0.8246 \\
\hline 40 & 5.070 & 3.093 & 2.025 & 1.069 \\
\hline 45 & 5.779 & 3.732 & 2.403 & 1.329 \\
\hline 50 & 6.497 & 4.377 & 2.776 & 1.601 \\
\hline 60 & 7.909 & 5.687 & 3.515 & 2.173 \\
\hline 70 & 9.213 & 7.006 & 4.237 & 2.769 \\
\hline 80 & 10.46 & 8.321 & 4.940 & 3.381 \\
\hline 90 & 11.56 & 9.617 & 5.615 & 4.002 \\
\hline 100 & 12.62 & 10.89 & 6.263 & 4.627 \\
\hline 110 & 13.59 & 12.14 & 6.885 & 5.254 \\
\hline 120 & 14.49 & 13.36 & 7.482 & 5.879 \\
\hline 130 & 15.32 & 14.55 & 8.053 & 6.500 \\
\hline 140 & 16.09 & 15.72 & 8.601 & 7.117 \\
\hline 150 & 16.81 & 16.85 & 9.124 & 7.729 \\
\hline 160 & 17.61 & 17.96 & 9.629 & 8.334 \\
\hline 170 & 18.45 & 19.06 & 10.12 & 8.932 \\
\hline 180 & 19.26 & 20.13 & 10.61 & 9.525 \\
\hline 190 & 20.05 & 21.19 & 11.08 & 10.11 \\
\hline 200 & 20.93 & 22.25 & 11.55 & 10.69 \\
\hline 210 & 21.81 & 23.29 & 12.02 & 11.27 \\
\hline 220 & 22.84 & 24.32 & 12.49 & 11.84 \\
\hline 230 & 22.82 & 25.35 & 12.95 & 12.40 \\
\hline 240 & 22.94 & 26.32 & 13.36 & 12.96 \\
\hline 250 & 23.66 & 27.27 & 13.75 & 13.52 \\
\hline 260 & 24.49 & 28.21 & 14.15 & 14.06 \\
\hline 270 & 26.10 & 29.16 & 14.56 & 14.60 \\
\hline 280 & 27.25 & 30.14 & 15.00 & 15.14 \\
\hline 290 & 27.79 & 31.10 & 15.43 & 15.68 \\
\hline 298.15 & 28.40 & 31.88 & 15.77 & 16.11 \\
\hline 300 & 28.59 & 32.06 & 15.85 & 16.21 \\
\hline 310 & 30.63 & 33.03 & 16.29 & 16.73 \\
\hline 320 & 32.99 & 34.04 & 16.78 & 17.26 \\
\hline
\end{tabular}

values of cell constants, which were correspondingly $K_{\mathrm{A}}=$ $185.65 \pm 0.43 \mathrm{mV} \mathrm{W}^{-1}$ and $K_{\mathrm{B}}=200.00 \pm 0.63 \mathrm{mV} \mathrm{W}^{-1}$. The uncertainty of the measurements of enthalpies of vaporization was not greater than $0.5-1.0 \%$ over a large range of saturated vapor pressures provided that the measured powers of heat flows did not exceed $0.5 \mathrm{~W}$. The calorimetric procedure is described in greater detail elsewhere (13).

\section{Results and Discussion}

Results of the low-temperature heat capacity measurements obtained in seven series of measurements are reported in Table I, where $C_{p, \mathrm{~m}}$ is the experimental molar heat capacity at the mean temperature of the experiment $\langle T\rangle$ and $\Delta T$ is the temperature increase of the calorimeter corrected for heat exchange with the environment. Care was taken to ensure that thermal equilibrium was achieved. Measurements between 5 and $12 \mathrm{~K}$ required unusually long equilibration times, and were 5-6 times greater than those typically noted for organic samples. The reason for the longer equilibration times is not clear; however, we suspect that it may result from slow adsorption/desorption of the helium heat-exchange gas upon the solid sample at these low temperatures. Examination of the heat capacity data (see Figure 1) reveals that there is a small anomaly in the $C_{p, m} / R$ versus $T$ curve around $217-235 \mathrm{~K}$ caused by a reversible solid-phase transformation. A second unexplained anomaly (not reversible, likely trace occluded solvent removal) is observed around $260-280 \mathrm{~K}$, and at higher temperatures there is a sharp increase in the $C_{p, m}$ of the substance. Inspection of the solid sample after the heat capacity measurements was finished showed no visual color change and no signs of thermal degradation.

Table II lists the thermodynamic functions of crystalline 2,4,6-trimethylbenzonitrile $N$-oxide calculated at every 5 or $10 \mathrm{~K}$ temperature change over the $0-320 \mathrm{~K}$ temperature interval. The Debye heat capacity equation was used in extrapolating measured heat capacity data to $T \rightarrow 0$ :

$$
C_{p, \mathrm{~m}}=3 R D\left(\theta_{\mathrm{D}} / T\right)
$$

where $\theta_{D}=79.4 \mathrm{~K}$ is the characteristic temperature based upon $C_{p, m}$ data in the temperature interval of 5.74-8.31 K. Calculated thermodynamic functions at $298.15 \mathrm{~K}$ are

$$
\begin{gathered}
C_{p, \mathrm{~m}}=236.10 \pm 0.94 \mathrm{~J} \mathrm{~mol}^{-1} \mathrm{~K}^{-1} \\
H^{\circ}{ }_{298.15}-H_{0}^{\circ}=39101 \pm 158 \mathrm{~J} \mathrm{~mol}^{-1} \\
S_{298.15}^{\circ}-S_{0}^{\circ}=265.08 \pm 1.15 \mathrm{~J} \mathrm{~mol}^{-1} \mathrm{~K}^{-1} \\
\left(H^{\circ}{ }_{298.15}-H_{0}^{\circ}\right) / T=131.15 \pm 0.53 \mathrm{~J} \mathrm{~mol}^{-1} \mathrm{~K}^{-1} \\
-\left(G^{\circ}{ }_{298.15}-H_{0}^{\circ}\right) / T=133.93 \pm 1.27 \mathrm{~J} \mathrm{~mol}^{-1} \mathrm{~K}^{-1}
\end{gathered}
$$

On the basis of an analysis of the nonregular contribution to the heat capacity over the 217-235 K temperature interval, the following thermodynamic functions have been computed:

$$
\begin{gathered}
T_{\mathrm{tr}}=224.3 \mathrm{~K} \\
\Delta_{\mathrm{tr}} H_{\mathrm{m}}=80 \pm 4 \mathrm{~J} \mathrm{~mol}^{-1} \\
\Delta_{\mathrm{tr}} S=0.35 \pm 0.02 \mathrm{~J} \mathrm{~mol}^{-1} \mathrm{~K}^{-1}
\end{gathered}
$$

for the reversible solid-phase transformation. Transition properties were based upon three sets of heat capacity measurements [one set is provided in Table I as series 6] over the temperature interval of $217-235 \mathrm{~K}$ :

$$
\begin{gathered}
\Delta_{\mathrm{tr}} H_{\mathrm{m}}=\int_{T=217}^{T=235} C_{p} \text { (excessive) } \mathrm{d} T \\
\Delta_{\mathrm{tr}} S=\int_{T=217}^{T=235}\left[C_{p} \text { (excessive) } / T\right] \mathrm{d} T
\end{gathered}
$$

where $C_{p}$ (excessive) represents the difference between the experimental and regular heat capacity; i.e., $C_{p}$ (excessive) $=$ $C_{p}$ (exp) $-C_{p}$ (reg). The value of $C_{p}$ (reg) was found by extrapolating the gradual parts of the heat capacity as a function of temperature, $C_{p}=f(T)$. The transition temperature was computed as the peak temperature in the $C_{p}$ versus $T$ curve (see Figure 1). Uncertainties represent the mean squared deviation of the mean arithmetic value by the 
Table III. Calorimetric Results for the Sublimation Enthalpy of 2,4,6-Trimethylbenzonitrile $N$-Oxidee

\begin{tabular}{cccrccr}
\hline $\begin{array}{c}\text { type } \\
\text { no. cell }\end{array}$ & \multicolumn{1}{c}{$m / \mathrm{g}$} & \multicolumn{1}{c}{$\tau_{2} / \mathrm{s}$} & $\begin{array}{c}\int_{\tau=0}^{\tau_{2}} \Delta E \\
\mathrm{~d} \tau /(\mathrm{mV} \text { s) }\end{array}$ & $\Delta_{\text {sub }} H / \mathrm{J}$ & $\begin{array}{c}\Delta_{\text {sub }} H_{\mathrm{m} /}^{\circ} \\
(\mathbf{k J ~ m o l}\end{array}$ \\
\hline 1 & A & 0.05405 & 20000 & 5416.0 & 29.173 & 87.01 \\
2 & A & 0.05249 & 10317 & 5333.3 & 28.728 & 88.22 \\
3 & A & 0.04345 & 16327 & 4403.2 & 23.718 & 87.99 \\
4 & B & 0.02062 & 9200 & 2226.4 & 11.132 & 87.01 \\
5 & B & 0.04465 & 5021 & 4844.0 & 24.220 & 87.44 \\
6 & B & 0.05655 & 19035 & 6111.9 & 30.559 & 87.42 \\
& & & & & & av: 87.52
\end{tabular}

a The average square deviation of the average arithmetic value is $0.20 \mathrm{~kJ} \mathrm{~mol}^{-1}$. Taking into account the Student's $t$ test criterion $(t$ $=2.571)$ for the $95 \%$ confidence interval, we obtain $\Delta_{\mathrm{sub}} H^{\circ} \mathrm{m}(313.5 \mathrm{~K})$ $=87.520 .53 \mathrm{~kJ} \mathrm{~mol}^{-1}$. Note: The sublimation enthalpy $\Delta_{\text {nub }} H$ of the specimen and the molar enthalpy of sublimation $\Delta_{\mathrm{ub}} \mathrm{H}_{\mathrm{m}}^{\circ}$ were calculated from the expressions $\Delta_{\text {nub }} H=K^{-1} \int_{r}^{r_{2}} \Delta E \mathrm{~d} \tau$ and $\Delta_{\text {sub }} H^{\circ}$ $=\left(\Delta_{\text {ub }} H\right) M / m$, where $m$ is the specimen mass, $M$ is the molar mass, $K$ is the calorimeter cell constant, $\Delta E$ is the thermocouple potential difference corresponding to the temperature imbalance between the cell and calorimeter thermostat at the moment $\tau$, and $\tau_{2}$ is the experiment duration.

Student's $t$ test factor $\left(t_{\mathrm{B}}=4.3\right)$ for three sets of replicate heat capacity measurements.

Sublimation measurements were performed on the sample as received via air mail and after subsequent purification by vacuum sublimation to remove trace impurities which may have resulted from prolonged shelf storage and/or X-ray inspections at airport security checkpoints. For the original sample four sets of measurements were performed; however, in every case the sample was not completely vaporized after $5 \mathrm{~h}$ in vacuum at $318.4 \mathrm{~K}$. A significant quantity of brown material was found on the bottom of the calorimetric cell. Because of the incomplete vaporization, the calculated enthalpies varied from 384 to $892 \mathrm{~J} \mathrm{~g}^{-1}$ and the values were not included in the statistical analysis. Six sets of measurements on the purified sample gave very reproducible sublimation enthalpies as shown in Table III. The average of $\Delta_{\text {sub }} H_{\mathrm{m}}^{\circ}(313.5 \mathrm{~K})=87.52 \pm 0.53 \mathrm{~kJ} \mathrm{~mol}^{-1}$ is in excellent agreement with an earlier value of $\Delta_{\mathrm{sub}} H^{\circ} \mathrm{m}(319.2 \mathrm{~K})=87.41$ $\pm 1.81 \mathrm{~kJ} \mathrm{~mol}^{-1}(10)$, which was based upon an integral Knudsen effusion vapor pressure method.

On the basis of these two values corrected to $298.15 \mathrm{~K}$, the recommended value of sublimation enthalpy is $\Delta \Delta_{\mathrm{cr}} H^{\circ}{ }_{\mathrm{m}}^{-}$ $(298.15 \mathrm{~K})=87.8 \pm 1.9 \mathrm{~kJ} \mathrm{~mol}^{-1}$. Assuming the residual entropy equals zero, $S^{\circ}{ }_{\mathrm{m}}(\mathrm{c}, 298.15 \mathrm{~K})=265.08 \mathrm{~J} \mathrm{~mol}^{-1} \mathrm{~K}^{-1}$. The saturated vapor pressure $P^{\circ}(298.15 \mathrm{~K})$ can be calculated by insignificant extrapolation of experimental data to 298.15 $\mathrm{K}$ using the polynomial dependence reported earlier (10). Then $P^{\circ}(298.15 \mathrm{~K})=0.109 \mathrm{~Pa}$. In accordance with this set of data, the standard entropy of the gaseous 2,4,6-trimethylbenzonitrile $N$-oxide at $298.15 \mathrm{~K}$ is equal to

$$
\begin{gathered}
S_{\mathrm{m}}^{\circ}(\mathrm{g}, 298.15 \mathrm{~K})=S_{\mathrm{m}}^{\circ}(\mathrm{c}, 298.15 \mathrm{~K})+ \\
\Delta_{\mathrm{cr}}^{\mathrm{g}} H^{\circ}{ }_{\mathrm{m}}(298.15 \mathrm{~K}) / 298.15 \mathrm{~K}+ \\
R \ln \left[P^{\circ}(298.15) / 101325 \mathrm{~Pa}\right]=445.3 \mathrm{~J} \mathrm{~mol}^{-1} \mathrm{~K}^{-1}
\end{gathered}
$$

\section{Literature Cited}

(1) Hanhela, P. J.; Raul, D. B. Aust. J. Chem. 1989, 42, 287.

(2) Hanhela, P. J.; Paul D. B. Aust. J. Chem. 1989, 42, 1257.

(3) Grundmann, C.; Grunanger, P. The Nitrile Oxides; SpringerVerlag: Berlin, 1971

(4) Torssell, K. B. G. Nitrile Oxides, Nitrones, and Nitronates in Organic Synthesis; VCH Publishers: New York, 1988; Chapter 2.

(5) Grundmann, C.; Dean, J. M. J. Org. Chem. 1965, 30, 2809

(6) Christl, M.; Warren, J. P.; Hawkins, B. L.; Roberts, J. D. J. Am. Chem. Soc. 1973, 95, 4392.

(7) Shiro, M.; Yamakawa, M.; Kobuta, T.; Koyama, H. J. Chem. Soc., Chem. Commun. 1968, 1409.

(8) Acree, W.E., Jr.; Tucker, S. A.; Zvaigzne, A. I.; Meng-Yen, Y.;Pilcher, G.; Ribeiro da Silva, M. D. M. C. J. Chem. Thermodyn. 1991, 23, 31 .

(9) Acree, W. E., Jr.; Tucker, S. A.; Pilcher, G. J. Chem. Thermodyn. $1992,24,213$

(10) Acree, W. E., Jr.; Simirsky, V. V.; Kozyro, A. A.; Krasulin, A. P.; Kabo, G. J.; Frenkel, M. L. J. Chem. Eng. Data 1992, 37, 131.

(11) Beltrame, P.; Gelli, G.; Loi, A. Nouv. J. Chim. 1981, 5, 453.

(12) Kabo, G. J.; Kozyro, A. A.; Krouk, V. S.; Sevruk, V. M.; Yursha, I. A.; Simirsky, V. V.; Gogolinsky, V. I. J. Chem. Thermodyn. 1992, 24,1 .

(13) Sevruk, V. M.; Simirsky, V. V.; Kabo, G. J.; Kozyro, A. A.; Krasulin A. P. Russ. J. Phys. Chem. 1990, 64, 118.

Received for review May 11, 1992. Revised August 10, 1992. Accepted October 28, 1992. 